\title{
On Quantum 3-Pass Protocol
}

\author{
Ahmed E* \\ Department of Mathematics, Faculty of Science, Egypt
}

Submission: November 22, 2017; Published: February 01, 2018

*Corresponding author: Ahmed E, Department of Mathematics, Faculty of Science, Mansoura 35516, Egypt, Email: magd45@yahoo.com

Abstract

Some proposed 3-pass protocols in quantum cryptography assumes that the qbits are 2-component. Here we propose a protocol without this assumption.

Keywords: cryptography; Three-pass protocol; Private decryption key; Three encrypted messages

\section{Opinion}

\section{Three pass protocol $[1,2]$}

In cryptography, the three-pass protocol for sending messages is a framework which allows one party to securely send a message to a second party without the need to exchange or distribute encryption keys. It is called the three-pass protocol because the sender and the receiver exchange three encrypted messages. The first three-pass protocol was developed by Adi Shamir circa 1980. The basic concept of the three-pass. Protocol is that each party has a private encryption key and a private decryption key. The two parties use their keys independently, first to encrypt the message, and then to decrypt the message.

The Three-Pass Protocol works as follows

o The sender chooses a private encryption key es and a corresponding decryption key The sender encrypts the message $m$ with the key es and sends the encrypted message to the receiver.

o The receiver chooses a private encryption key and a corresponding decryption key er and encrypts the first message $E(e s, m)$ with the key $d r$ and sends the doubly encrypted message $E(e r, E(e s, m)$ back to the sender.

o The sender decrypts the second message with the key $d s$. Because of the commutativity property described above $D(d s, E(e r, E(e s, m)))=E(e r, m)$ which is the message encrypted with only the receiver's private key. The sender sends this to the receiver.

The receiver can now decrypt the message using the key $d r$, namely $D(d r, E(e r, m))=m$ the original message. Notice that all of the operations involving the sender's private keys es and $d s$ are performed by the sender, and all of the operations involving the receiver's private keys $e r$ and $d r$ are performed by the receiver, so that neither party needs to know the other party's keys.

\section{Quantum 3-pass protocol}

Recently quantum 3-pass protocol has been proposed [3]. It was assumed that the qbits are 2-component hence they use the fact that the group $\mathrm{SO}(2)$ is commutative. This is Not true for $\mathrm{SO}(\mathrm{n}), \mathrm{n}>2$. Here we propose the following protocol which does not make this assumption. Assume that sender A sends a string of qbits $\{q b(1), q b(2) \ldots q b(s)\}$ to a receiver B. He receives them which causes some errors according to Uncertainty principle [4]. The receiver B sends back the Extended string $\left\{q b^{\prime}(1), q b^{\prime}(2) \ldots q b^{\prime}(s), q b(s+1), \ldots q b(s+r)\right\}$. When the sender A receive it the correct subset of $\left\{q b^{\prime}(1), q b^{\prime}(2) \ldots q b^{\prime}(s)\right\}$ will form her key. The extended string is sent back to the receiver $\mathrm{B}$ and he gets $\left\{q b^{\prime}(1), q b^{\prime}(2) \ldots q b^{\prime}(s), q b^{\prime}(s+1), \ldots q b^{\prime}(s+r)\right\}$. The correct subset of the string $\left\{q b^{\prime}(s+1), \ldots q b^{\prime}(s+r)\right\}$ will be his key. No assumptions are made on the number of components used for each qbit.

\section{References}

1. Feige U, Fiat A, Shamir A (1987) Zero knowledge proofs of identity. Proceedings of the nineteenth annual acm symposium on theory of computing, New York, USA pp. 210-217.

2. 3-pass protocol, Wikipedia.

3. Yoshito K, Seong MY (2009) Quantum Three-Pass Protocol: Key Distribution Using Quantum Superposition States. IJNSA Volume 1.

4. Schiff LI (1980) Quantum mechanics. McGraw-Hill, New York, USA. 
This work is licensed under Creative Commons Attribution 4.0 Licens

DOI: 10.19080/BBOAJ.2018.04.555648
Your next submission with Juniper Publishers will reach you the below assets

- Quality Editorial service

- Swift Peer Review

- Reprints availability

- E-prints Service

- Manuscript Podcast for convenient understanding

- Global attainment for your research

- Manuscript accessibility in different formats ( Pdf, E-pub, Full Text, Audio)

- Unceasing customer service

Track the below URL for one-step submission https://juniperpublishers.com/online-submission.php 